Article

\title{
Molecular Imprinted Based Quartz Crystal Microbalance Sensors for Bacteria and Spores ${ }^{\dagger}$
}

\author{
Usman Latif $^{1,2}{ }^{2}$, Serpil Can ${ }^{1}$, Hermann F. Sussitz ${ }^{1}$ and Franz L. Dickert ${ }^{1, *}$ (iD) \\ 1 Department of Analytical Chemistry, University of Vienna, Waehringer Str. 38, A-1090 Wien, Austria; \\ usmanlatif04@gmail.com (U.L.); cserpil@hotmail.com (S.C.); hermann.sussitz@univie.ac.at (H.F.S.) \\ 2 Interdisciplinary Research Centre in Biomedical Materials, COMSATS University Islamabad, \\ Lahore Campus, Lahore 54600, Pakistan \\ * Correspondence: Franz.Dickert@univie.ac.at \\ + Dedicated to Prof. Dr. Heinz Hoffmann on the occasion of his 85th birthday.
}

Received: 24 June 2020; Accepted: 30 July 2020; Published: 4 August 2020

\begin{abstract}
A molecular imprinting strategy was combined with mass-sensitive transducers to generate robust and reliable biomimetic sensor systems for the detection of bioparticles. The patterning of polymers with bioanalytes enabled us to detect Escherichia coli (E. coli) bacteria with quartz crystal microbalance $(\mathrm{QCM})$. The QCM sensor results were compared with direct Atomic Force Microscopy (AFM) measurements-bacteria cells adhering to the sensor coatings were counted. The recognition sites generated by Bacillus subtilis (B. subtilis) spores could successfully and reversibly recognize the template analyte and ensured rapid sensing. Cross sensitive measurements clearly showed the advantage of the molecular imprinting strategy, by which spores of Bacillus species (subtilis and thuringiensis) could easily be differentiated and selectively detected. The growth of B. subtilis from its spores was observed at $42{ }^{\circ} \mathrm{C}$ in appropriate nutrient solution of glucose and ammonium sulfate over a period of $15 \mathrm{~h}$. Moreover, the growth of $B$. subtilis bacteria from its respective spores was studied by increasing the glucose concentration until saturation effect of the sensor. The polymeric sensor coatings were patterned to fix the $B$. subtilis in order to investigate osmotic effects according to a frequency response of $400 \mathrm{~Hz}$ by altering the ionic strength of $0.1 \mathrm{M}$.
\end{abstract}

Keywords: monitoring cells and spores; molecular imprinting; QCM sensors; AFM

\section{Introduction}

There is an urgent demand for the development of selective, sensitive and rapid bacteria sensors [1] in the fields of health care, environmental monitoring, food analysis, and security [2]. Illnesses caused by pathogenic bacteria are always a great public health problem [3]. These pathogenic bacteria will continue to cause outbreaks and deaths throughout the world [4]. The rod-shaped Escherichia coli bacteria [5,6] are found in the human gut. However, certain strains of Escherichia coli (E. coli) can cause severe food poisoning and Urinary Tract Infection (UTI). It is estimated that about $90 \%$ of UTI infections could be caused by E. coli [7]. Pathogenic strains of E. coli are some of the most hazardous bacteria, causing persistent infantile diarrhea and mortality among children, particularly in developing countries [8,9]. It can produce a Shiga-like toxin and cause life-threatening hemorrhagic colitis, renal failure and meningitis [10]. The most pathogenic strain of E. coli is the second leading cause of death in children of age less than 5 years, and causes 1.3 million deaths annually, worldwide [11]. Therefore, it remains a challenge to develop a rapid real time detection system for public health safety and biothreat prevention.

The Gram-positive, rod-shaped species of the Bacillus genus, such as Bacillus subtilis (B. subtilis), Bacillus thuringiensis (B. thuringiensis) [12], Bacillus cereus (B. cereus), and Bacillus anthracis (B. anthracis), 
produce endospores as part of their life cycle [13] in response to nutrient deprivation [14]. These ametabolic spores are produced from the vegetative mother cells in a series of differentiating processes. These spores can withstand radiation, heat, and other harsh conditions for a long period of time [15]. The spores will complete their life cycle by producing the vegetative cells via a process of germination under appropriate conditions [16]. The spores of pathogenic Bacillus species can cause different diseases such as anthrax [17] if the spores of B. anthracis are acquired by the host through skin, by inhalation, or by ingestion. $B$. anthracis is known as a biological weapon that was used throughout the 20th century, and is a potential bioterrorist tool due to its highly pathogenic nature [18]. Thus, it is classified as a class A bioterrorism agent [19]. Recent studies have shown that Bacillus species are genetically similar to each other.

Polymerase chain reactions (PCRs) that rely on the identification of specific gene sequence and nucleic acid-based detection may be sensitive, but extensive pretreatment steps are required. Thus, these techniques are not feasible for use in real-time analysis because they require well-trained personnel, significant time commitment, and several assay steps [20]. ELISA assays for Bacillus species rely on colorimetric or electric detection, which usually needs a second validation. Antibody-based biosensors may not be ideal for the detection of these pathogens because of their denaturation (loss of function) when exposed to harsh environmental conditions. Other technologies for spore detection available in the literature include chromatography [21,22], fluorescence [23], luminescence [24], mass spectrometry [25], Fourier transform infrared spectroscopy [26], and Raman spectroscopy [27-29]. Although these technologies are very accurate, they often lack sensitivity when compromised for portability. Thus, a simple and accurate detection of Bacillus spores is still an active area of research, especially in real-time samples. In this context, the aim of this study is to design a rapid detection system for quantitative assessment of pathogenic organisms in real time.

The design of highly sensitive and selective synthetic receptors is very important. Often, they are combined with different types of transducers, as well as with QCMs to develop a sensor system. We used the strategy of supramolecular chemistry, as well as molecular imprinting, to design receptors for various target analytes. However, we also used natural antibodies as receptors, and their results were compared with imprinting [30-34].

Thus, this paper introduces the application of biomimetic sensors in which stability and robustness of polymers are combined with recognition capabilities of biological systems. These so-called 'smart materials' are synthesized by applying a surface imprinting strategy. The molecular imprinted polymers (MIPs) [35] are combined with quartz crystal microbalances (QCMs) [36] to develop detection systems for both bacteria (E. coli) and spores (Bacillus). In this way, the growth of bacteria from its spores, the behavior of organisms under different nutrient solution and their reaction to environmental changes are investigated.

\section{Materials and Methods}

All the chemicals were purchased from Sigma-Aldrich and Fluka in the highest available purity and were used without further processing. Escherichia coli bacteria strain W and Bacillus subtilis spores were obtained from LGC Standards GmbH, Wesel Germany.

\subsection{Surface Imprinting of Microorganisms}

The bulk molecular imprinting technique is very efficient for patterning the layer to diagnose small molecules, while for introducing recognition properties in a polymer layer for larger molecules and biological species of sizes ranging up to few micrometers, surface imprinting is a most promising technique [37]. In this study, recognition layers for bacteria as well as spores are developed by using these cells as a stamp for surface imprinting. The assembling of cells/spores on glass, and their subsequent use of these stamps for the surface imprinting the polymer layer, will produce recognition sites for the analyte [38]. In this procedure, a layer of prepolymer (polyurethane) is spin coated on a transducer of uniform desired thickness. The polyurethane is prepared from $42.2 \mathrm{mg}$ of 
4,4'-diisocyanato diphenylmethane, $42.2 \mathrm{mg}$ of poly 4-vinylphenol and $15.6 \mathrm{mg}$ of phloroglucinol as cross linker, while using $100 \mu \mathrm{L}$ of THF as solvent. The mixture is heated at $70^{\circ} \mathrm{C}$ until gelation point. Then, the prepolymer is spin coated on dual electrode quartz plates at $2500 \mathrm{rpm}$. A stamp was prepared by depositing a thin film of bacteria or spores on $8 \times 8 \mathrm{~mm}$ glass slides. Afterwards, a bacteria or spore stamp is pressed onto the prepolymer coating and subsequently clamped to emboss the stamp on the spin-coated prepolymer. Then, it is allowed to stand overnight to align the polymer chains according to the microorganism surface. The stamps are removed after complete polymerization, leaving behind a highly cross-linked polymer imprint, as shown schematically in Figure 1. These recognition sites are geometrically and chemically adapted to the analyte, thereby enabling the selective and reversible interaction of respective microorganisms.

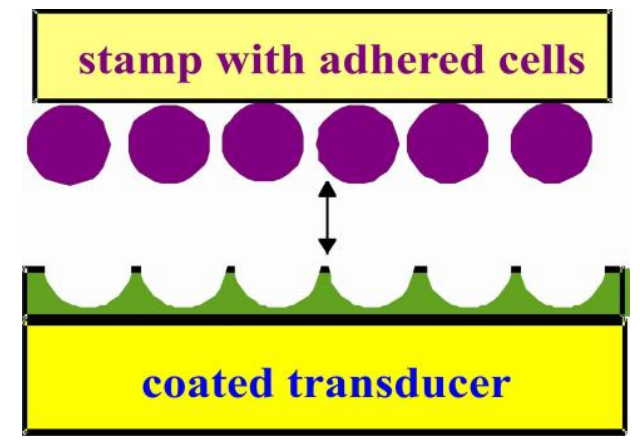

Figure 1. A QCM coated with a pre-polymer followed by surface patterning with a stamp possessing adhered cells.

\subsection{Measurements}

Mass-sensitive sensors were prepared by screen printing a desired electrode structure on commercially available AT-cut $10 \mathrm{MHz}$ quartz plates (Great Microtama Electronics Indonesia) with a thickness of $168 \mu \mathrm{m}$ and a diameter of $14.0 \mathrm{~mm}$. These printed quartz discs are burnt at $400{ }^{\circ} \mathrm{C}$ for two hours after screen printing (Hanau, Degussa) and mounted on a measuring chamber. A dual electrode geometry ( $4.5 \mathrm{~mm}$ diameter) is printed on the same quartz plates in order to compensate for variations in temperature and viscosity via differential measurements. We always use two or three electrode systems for measurements. Therefore, temperature effects or non-selective adsorptions were compensated for through differential measurements. The main contributions to temperature dependencies are due to viscosity changes in water. In this way, the selective interactions of imprinted electrodes can be compared with the non-selective interactions of reference electrode towards target analyte. The resonance frequency of QCM will decrease proportionally to the mass load, according to the Sauerbrey equation [39]. The QCM-D works in the time domain, while the frequency domain can be evaluated by, e.g., Fourier transformation. Thus, the decay corresponds to the quality of quartz. The quality of the QCM can be investigated by using network analyzer measurements. The electrode pairs on the quartz were placed in the feedback loop of the self-made oscillator as a frequency-determining element. Any load on the oscillator output dampens and detunes the oscillator. As a countermeasure, a buffer amplifier is used to decouple the oscillator output from the following stage. These arrangements were used for each electrode pair. The resulting frequency of QCM was read out by frequency counter (Agilent 53131A) via a custom-made oscillating circuit and transferred to computer by LabVIEW software. The oscillating circuit is self-made and was fabricated in our laboratory. The frequency response of each electrode pair and its difference can be visualized on the computer.

The AFM measurements were carried out by using Veeco/digital instruments Nanoscope IIIa in contact mode, while the correction of images was done with AFM control software. 


\section{Results and Discussion}

\subsection{Sensor Characteristics-Comparison of QCM with AFM Measurements}

The detection of E. coli bacteria was performed by using a QCM having fundamental frequency of $10 \mathrm{MHz}$. The measurement was carried out in a flow cell. The mass-sensitive transducer was a dual channel crystal in which one electrode was coated with bacteria imprinted highly cross-linked polyurethane, whereas, the other electrode was coated with non-imprinted polymer. The second channel on the quartz disc serves as a reference channel which compensates for non-selective responses. During these measurements, the reversibility of cell adhesion and dissociation was analyzed, while the time constants for these processes were in the range of few minutes. The sensor responses for different concentrations of E. coli bacteria are shown in Figure 2. The sensor responses are based on differential measurements.

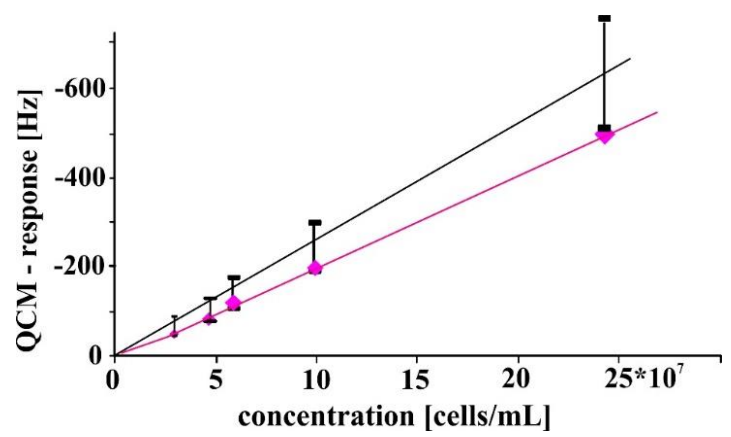

Figure 2. $10 \mathrm{MHz}$ QCM frequency response of Escherichia coli bacteria as a function of cell concentrations $(\diamond)$, compared to AFM-measurements (I) by counting adhered cells.

In Figure 2, the QCM sensor responses ( $\diamond$ ) are compared with AFM measurements (I) by counting the adhered cells. The inaccuracy in the counting procedure was mostly caused by the washing process. The measurements were conducted in triplicate. The picture depicts a linear relationship between a change in quartz resonant frequency with respect to changes in concentrations of E. coli. This linear relationship clearly shows that interaction sites on the quartz surface are not totally occupied by the bio-analytes; otherwise, a saturation effect would be observed to flatten off the isotherm of adsorption at higher concentrations. This problem was discussed in our previous paper [39], where cell adhesion to the surface was studied. Optimized printing yields receptor sites for cells which approximately follow the Sauerbrey equation for their re-inclusion. A further hint gives a rough accordance between the two dependencies in Figure 2. The frequency of QCM is directly related to the mass adhered to the surface. Coating and assembled particles are properly anchored to the surface leading to frequency diminishing. This is why these sensor responses can be directly compared with AFM measurements.

In AFM measurements, the mass-sensitive surface must be conditioned in order to compare with the QCM responses. At first, the templated QCM sensor layer is exposed to water for equilibration and subsequently to a distinct concentration $\left(6.3 \times 10^{7}\right.$ cells $\left./ \mathrm{mL}\right)$ of bacteria. The interaction sites incorporate bio-analytes and an equilibrium is established in almost ten minutes. Afterwards, non-selectively attached bacteria are removed by washing with water for one second. Then, solvent water is evaporated in order to count the bacteria by using contact mode of AFM as shown in Figure 3.

These adhered E. coli strain $W$ bacteria can be seen in this picture. There should be a monolayer adherence of bacteria with sensor layer which can be achieved by optimizing the volume and concentration of bacteria solution. Otherwise, the first layer could not unambiguously be detected since overlying cells which will cover the first layer. The multilayer adsorption of bacteria is avoided by optimizing volume and concentration of bacteria solutions. The AFM and QCM data can be related by the density and geometry of bacteria which have density nearly to $1.1 \mathrm{~g} / \mathrm{mL}$ [40]. A mass of $1 \mu \mathrm{g}$ will give a frequency response of $610 \mathrm{~Hz}$, which was calibrated with polyvinylchloride coatings. 
Thus, a AFM counting procedure and frequency measurements with QCMs can directly be correlated with each other. Quadratic areas on the QCM were analyzed by AFM with respect to adhered bacteria. Quadratic areas of $50 \mu \mathrm{m} * 50 \mu \mathrm{m}$ were considered at highest concentration in Figure 2. An average number of 83 bacteria were detected on these restricted surfaces with a mean length of $2.25 \mu \mathrm{m}$ for Escherichia coli. Then the mass can be calculated for this rod like bacteria with an approximate diameter of $1 \mu \mathrm{m}$ [5]. The dimensions of the areas were enhanced at lower concentrations to improve an accuracy in bacteria number. The satisfying accordance of these different measuring principles can be seen in in Figure 2.

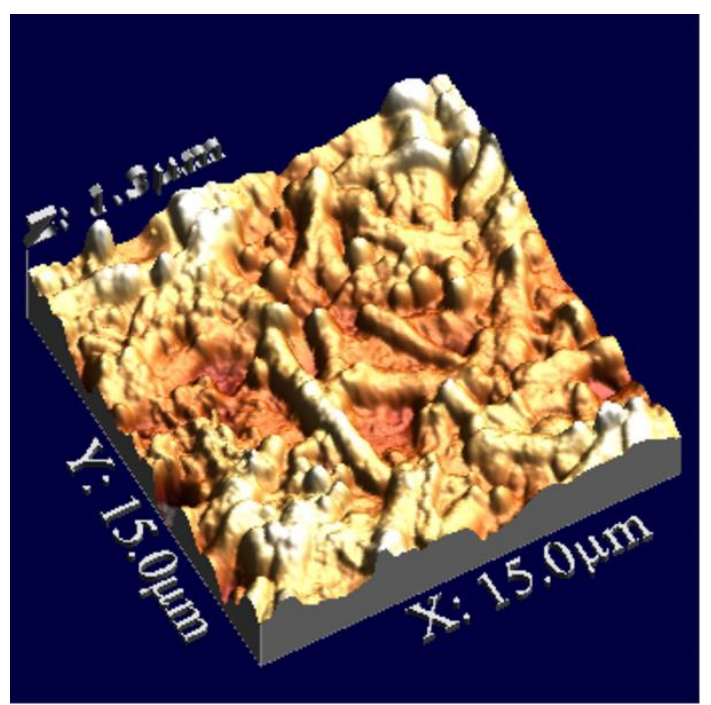

Figure 3. AFM measurements (contact mode) of E. coli strain W assembled on sensor layers.

A diminishing frequency response (Sauerbrey behavior) of mass-sensitive sensor clearly shows a rigid solid nature of sensitive layer and adhered bio-analytes. This observation shows that bacteria are tightly bound to the recognition sites which are generated by templating the polyurethane layer. Whereas, the bacteria which are not tightly incorporated by pre-organized cavities will not contribute significantly in lowering resonance frequency of mass-sensitive sensor. Thus, a short washing step of sensor coating (with adhered bacteria) allows us to differentiate between the analytes that are bound to the cavities than those that are loosely bound.

\subsection{Detection of Spores}

Pathogenic species of Bacillus bacteria is a great threat to mankind. Bacillus species will produce highly robust endospores that can withstand harsh conditions such as insufficient nutrition. The spores of Bacillus anthracis are important because of their high potential threat in bio-terrorism. The spores of $B$. subtilis and B. thuringiensis are used as model systems in order to develop a sensor platform for anthrax spore detection. The spores can directly be used for stamping highly cross linked prepolymerized polyurethane.

A sensor for spores of B. subtilis is developed by using dual channel QCMs of fundamental frequency of $10 \mathrm{MHz}$ by the procedure mentioned in experimental section. An appreciable sensor response is obtained by imprinted channel when it selectively recognizes the templated analyte in comparison to non-imprinted material as shown in Figure 4. The measurement shows that imprinting of Bacillus spores is successful and recognition sites reversibly bound to the analyte which ensures the guarantee for rapid sensing of bioanalytes.

Cross sensitivities of different recognition layers against spores of $B$. thuringiensis and subtilis are represented in Figure 5. These results are obtained by comparing the sensor responses of two different QCM sensors whose sensitive layers are templated with spores of B. thuringiensis and subtilis, 
respectively. The fabricated sensors show substantial frequency responses towards their templated analytes, with minor cross effects being observed. This cross sensitive behavior does not significantly depend on the differences in size and shape of spores, since they have similar dimensions in the range of 3-4 $\mu \mathrm{m}$. The selective frequency responses observed are mainly due to surface properties of bio-particles. These surface characteristics of spores are exploited during imprinting process to achieve very strong and selective interactions between receptor sites and bio-particles. This kind of selective behavior clearly shows the success of the pattern imprinted on the recognition layer, which can only be realized by a suitable polymer, and the degree to which it forms all types of interactions with the template [41].

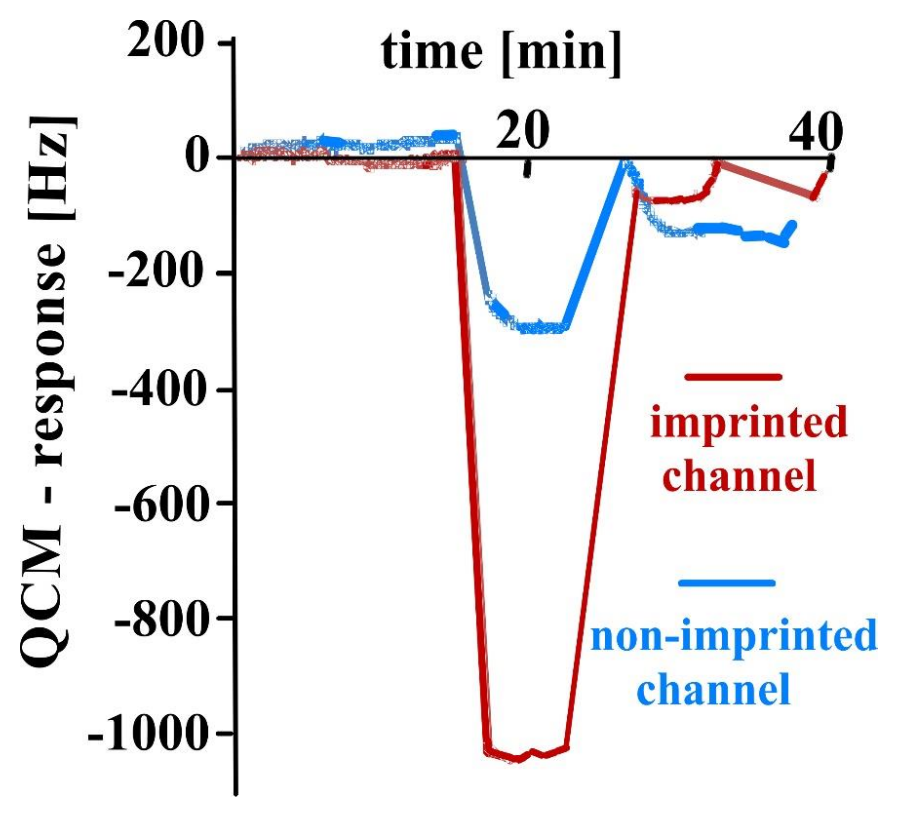

Figure 4. Mass-sensitive sensor responses to bacteria subtilis spores to imprinted and non-imprinted dual electrodes as a function of time.

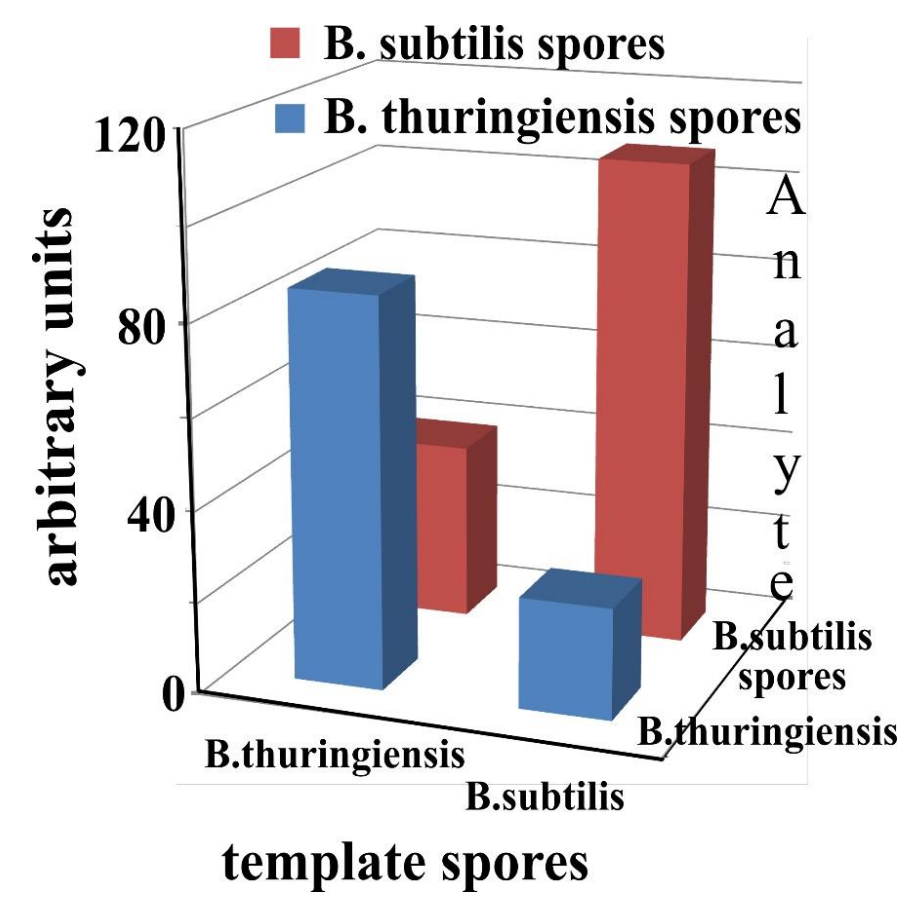

Figure 5. Cross sensitivities of B. subtilis and B. thuringiensis spores imprinted sensors. 


\subsection{Biotechnology-Monitoring Bacterial Growth in Nutrient Solutions by QCM Sensors}

Bacteria will grow from their respective spores in the presence of a nutrient solution. A nutrient solution containing important ingredients, e.g., glucose, hydrolyzed proteins, ammonium sulfates, phosphates, and other inorganic salts were provided to spores of Bacillus subtilis. The spores transformed to $B$. subtilis bacteria after an incubation period of approximately $6 \mathrm{~h}$. The growth of $B$. subtilis from its spores can be monitored by coating a recognition layer on QCM transducer, which should be selective and sensitive to the targeted analyte. Again, a dual channel $10 \mathrm{MHz}$ QCM sensor was developed for monitoring the growth of bacteria subtilis. One electrode of the dual channel QCM is covered with a bacteria subtilis-imprinted layer, whereas the second, non-imprinted electrode serves as a reference electrode to compensate for interferences caused by unselective ingredients of the nutrient solution and temperature fluctuations. The measurement shows a gravimetric sensor response of the QCM sensor when adding spores in a nutrient solution of $2-10 \%$ glucose at a temperature of $42{ }^{\circ} \mathrm{C}$ at $7.2 \mathrm{pH}$. The recognition layer is designed to selectively incorporate the templated analyte $B$. subtilis bacteria. Measurements are conducted in order to study the bacteria growth with increasing amounts of glucose in the nutrient solution. The results show the dependence of bacteria transformation from their respective spores on glucose concentration. The decrease in frequency of the mass-sensitive sensor is attributed to the transformation of spores into bacteria, which are recognized by templated layer. The growth of bacteria is continuously monitored for several hours in real time, and the results are simultaneously confirmed by repeated bacterial counts. In agreement with the observed effects, the frequency of the mass-sensitive sensor decreases to approximately $1200 \mathrm{~Hz}$ in $15 \mathrm{~h}$, with an increase in glucose concentration as shown in Figure 6. It will be stopped only by a deficiency of nutrients. In this case, the cells are transformed to spores again. An increase in glucose concentration to $10 \%$ leads to a saturation effect in sensor response. The interaction level of the QCM sensor can be estimated by taking into account the sensitive area of templated layer on the QCM, and the mass and size of subtilis bacteria.

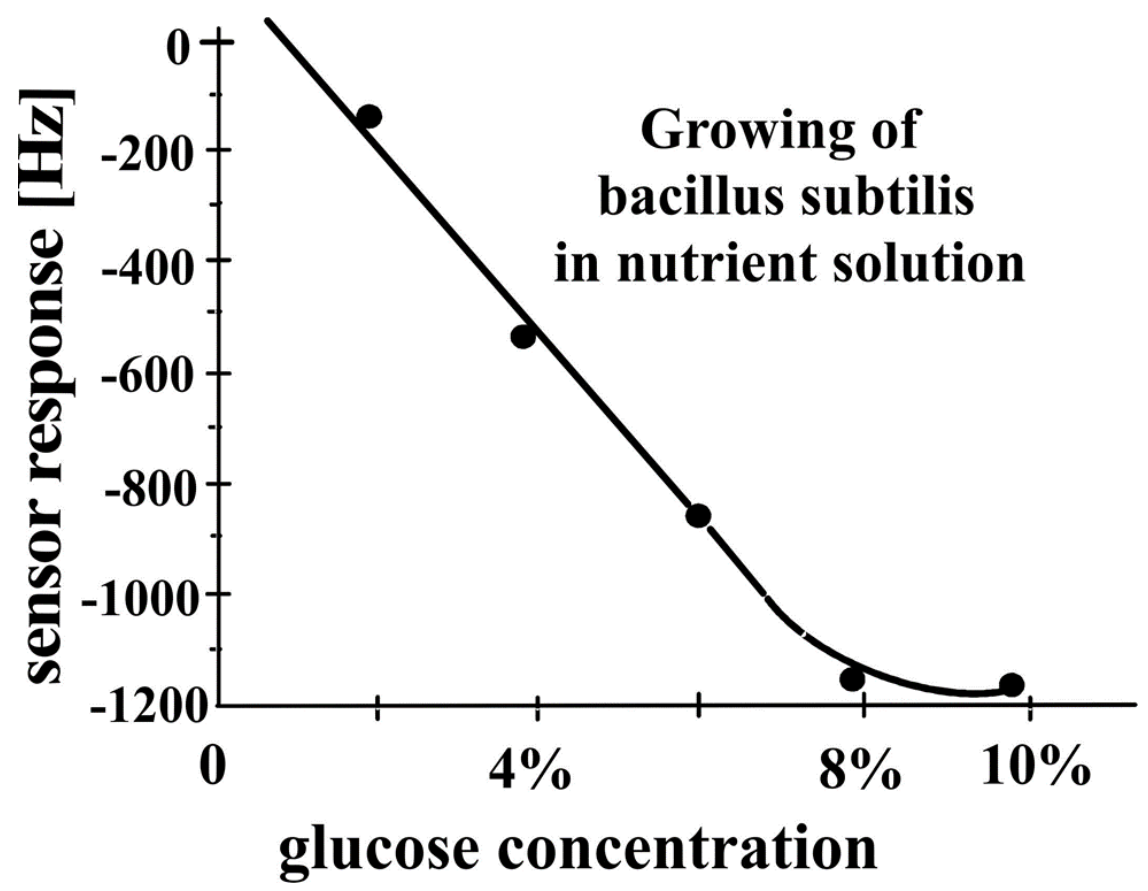

Figure 6. Monitoring the growth of B. subtilis from its spores in nutrient solution as a function of glucose concentration. 
A frequency shift of approximately $0.6 \mathrm{~Hz}$ of a $10 \mathrm{MHz}$ quartz crystal microbalance is roughly equal to $1 \mathrm{ng}$ mass load. The bacterium subtilis has about a rod-like shape with a diameter of $1 \mu \mathrm{m}$ and a length of $2.5 \mu \mathrm{m}$, as determined by AFM. This rod occupies almost $3 \mu \mathrm{m}^{2}$ on the imprinted electrode surface, if closely packed. An electrode with $4.5 \mathrm{~mm}$ diameter can achieve $5.3 \times 10^{6}$ interaction sites for the bacterium subtilis. The mass of the bacterium subtilis can be estimated in an analogous way as for E. coli. Again, the density of the bacterium is taken to be $1.1 \mathrm{~g} / \mathrm{cm}^{3}$. Thus, the bacterium subtilis has a weight of $2.15 \times 10^{-6} \mu \mathrm{g}$. The maximum overall mass of all adhered bacteria can be calculated to be equal to $11.4 \mu \mathrm{g}$. This mass loading would lead to a frequency shift of $6800 \mathrm{~Hz}$. This exceeds the response in Figure 6 by more than a factor of 5. Regardless of the rather complex mixture of various interfering compounds, the growth of bacteria from their spores can easily be monitored by the developed sensor.

The diameter of the gold electrode of QCM is 4-5 mm, which corresponds to an area of roughly $1.3 \times 10^{7} \mu \mathrm{m}^{2}$. Thus, an ideal imprinted surface contains around $4 \times 10^{6}$ interaction sites. A frequency shift of $1200 \mathrm{~Hz}$ corresponds to $12 \times 10^{8}$ subtilis bacteria, which can easily be accommodated in the templated sites. Regardless of the rather complex mixture of various interfering compounds, the growth of bacteria from their spores can easily be monitored by the developed sensor.

Molecular imprinting technology helps to design materials for the detection of either chemical or biological substances for sensing purposes. These recognition materials are able to bind the analyte in a selective and reversible manner, with limited binding constants. The characteristics of the MIP can be tuned in such a way to bind the analyte very strongly by the recognition layer and hence to prevent its release from the templated cavities. This can be achieved by a higher sensor layer in which bacteria are fixed in deeper holes. Enhanced enthalpic interactions between bacteria and sensor layer will lead to a drastically reduced dissociation rate. In such a sensor system, the subtilis bacteria are stuck almost irreversibly in the templated polymer and thus will remain immobilized on the surface. The QCM transducers coated with such an imprinted layer are highly suitable for monitoring processes taking place directly in the biospecies, as shown in Figure 7. The QCM sensor on which the bacteria subtilis are tightly bound to the surface are exposed to water and electrolyte solution. This process will not increase the number of bacteria subtilis, as water does not contain any nutrients for their growth, but it will change the water content inside the biospecies due to osmosis. This living sensor is exposed to water for almost $8 \mathrm{~h}$, and subsequently, a solution of sodium chloride is added in the same flow cell. This measurement is carried out to study the dehydration of biospecies, the moment they expose to salt solution. The frequency of the QCM sensor starts rising immediately after the addition of salt solution, which indicates the decrease in mass. The frequency of the sensor steadily increases for about $7 \mathrm{~h}$ to $400 \mathrm{~Hz}$. After $15 \mathrm{~h}$, the sensor system is flushed with water in order to reverse the effect. From this measurement, we can say that the behavior of living organisms under different environmental conditions can be studied by using these sensing platforms.

The conditions for the validity of the Sauerbrey equation have already been established. Fluctuations of the coating in a distinct time range will lead to energy absorption, even to an Anti-Sauerbrey behavior. The phenomenon has already been explained in detail in literature. An anti-Sauerbrey effect would be observed if imprinted sites are not perfectly fit for the template. This effect was proved by using network analyzer measurements. Thus, it can be concluded that the effects described in this paper can be interpreted as nearly Sauerbrey behavior. A further hint is given in the rough accordance between the two dependencies, as shown in Figure 2.

The effect in Figure 7 is an osmotic phenomenon, since ionic strength was enhanced, whereas the loss of water is a mass effect. 


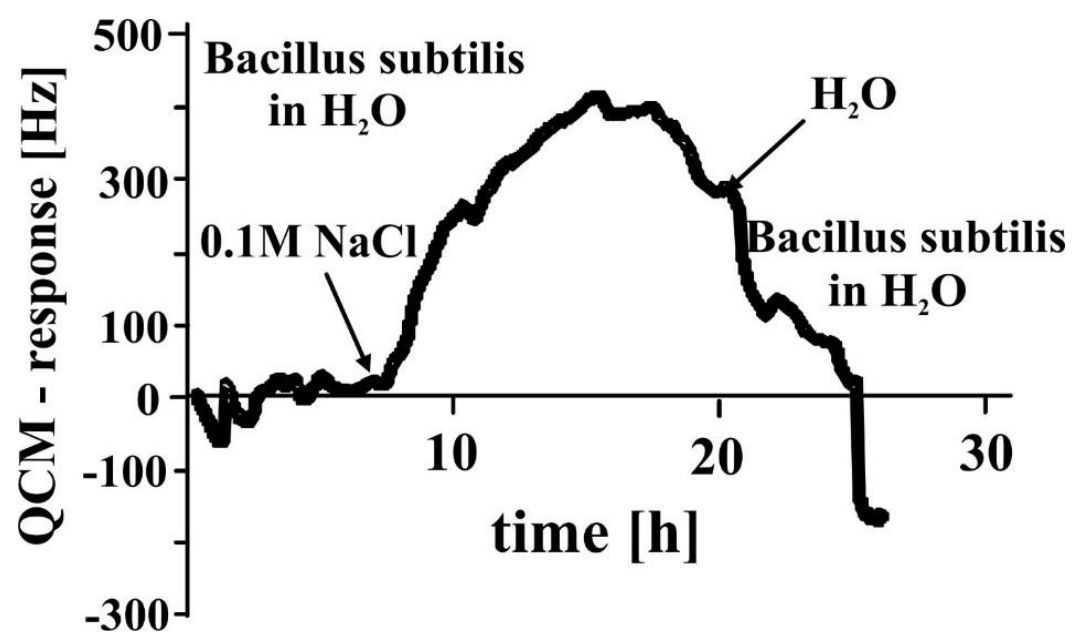

Figure 7. Bacillus subtilis adhered tightly to polyurethane coating exhibits osmotic effects on electrolyte addition.

\section{Conclusions}

Biomimetic imprinting strategies lead to the generation of more robust and stable receptors with the recognition capabilities of biological systems. Their combination with sensor devices, especially mass-sensitive transducers, allows the selective detection of bioanalytes such as bacteria and their respective spores. Further improvements are possible with SAW devices [42]. The surface imprinted polyurethane coatings are applied to quartz crystal microbalances to directly detect the bioanalytes, as well as to observe changes in environmental effects. Spores of Bacillus subtilis were chosen as a model organism to develop a sensor system for Bacillus anthracis spores, which cause the dangerous disease 'anthrax'. Careful patterning of polymer sensor coatings results in the differentiation of the spores of Bacillus species i.e., subtilis and thuringiensis. The selective detection of microorganisms is carried out in a complex nutrient solution of glucose and ammonium sulfate. Growth of Bacillus subtilis from its spores was analyzed over a period of $15 \mathrm{~h}$, where the method was proved to be highly suitable for application in on-line monitoring systems. These biomimetic imprinted sensors can also help us to understand the behavior of microorganisms under different environmental conditions.

Author Contributions: All authors made significant contributions to this research article. F.L.D. conceived the idea and U.L. designed the customized sensor setups for data acquisition. S.C. and H.F.S. performed the experiments. U.L. and F.L.D. contributed to paper writing, and the final version of the manuscript was prepared after several rounds of critical revisions. All authors have read and agreed to the published version of the manuscript.

Funding: This research received no external funding.

Conflicts of Interest: The authors declare no conflict of interest.

\section{References}

1. Dantism, S.; Röhlen, D.; Wagner, T.; Wagner, P.; Schöning, M.J. A laps-based differential sensor for parallelized metabolism monitoring of various bacteria. Sensors 2019, 19, 4692. [CrossRef] [PubMed]

2. Dechtrirat, D.; Gajovic-Eichelmann, N.; Wojcik, F.; Hartmann, L.; Bier, F.F.; Scheller, F.W. Electrochemical displacement sensor based on ferrocene boronic acid tracer and immobilized glycan for saccharide binding proteins and e. Coli. Biosens. Bioelectron. 2014, 58, 1-8. [CrossRef] [PubMed]

3. Lu, L.; Jun, S. Evaluation of a microwire sensor functionalized to detect escherichia coli bacterial cells. Biosens. Bioelectron. 2012, 36, 257-261. [CrossRef]

4. Wang, Y.; Ping, J.; Ye, Z.; Wu, J.; Ying, Y. Impedimetric immunosensor based on gold nanoparticles modified graphene paper for label-free detection of escherichia coli o157:H7. Biosens. Bioelectron. 2013, 49, 492-498. [CrossRef] 
5. Pierucci, O. Dimensions of escherichia coli at various growth rates: Model for envelope growth. J. Bacteriol. 1978, 135, 559-574. [CrossRef] [PubMed]

6. Yu, X.; Chen, F.; Wang, R.; Li, Y. Whole-bacterium selex of DNA aptamers for rapid detection of e.Coli o157:H7 using a qcm sensor. J. Biotechnol. 2018, 266, 39-49. [CrossRef]

7. Basu, P.K.; Indukuri, D.; Keshavan, S.; Navratna, V.; Vanjari, S.R.K.; Raghavan, S.; Bhat, N. Graphene based e. Coli sensor on flexible acetate sheet. Sens Actuators B Chem. 2014, 190, 342-347. [CrossRef]

8. Levine, M.M. Escherichia coli that cause diarrhea: Enterotoxigenic, enteropathogenic, enteroinvasive, enterohemorrhagic, and enteroadherent. J. Infect. Dis. 1987, 155, 377-389. [CrossRef]

9. Horner, S.R.; Mace, C.R.; Rothberg, L.J.; Miller, B.L. A proteomic biosensor for enteropathogenic e. Coli. Biosens. Bioelectron. 2006, 21, 1659-1663. [CrossRef]

10. Li, Y.; Afrasiabi, R.; Fathi, F.; Wang, N.; Xiang, C.; Love, R.; She, Z.; Kraatz, H.-B. Impedance based detection of pathogenic e. Coli o157:H7 using a ferrocene-antimicrobial peptide modified biosensor. Biosens. Bioelectron. 2014, 58, 193-199. [CrossRef]

11. Zhang, W.; Luo, C.; Zhong, L.; Nie, S.; Cheng, W.; Zhao, D.; Ding, S. Sensitive detection of enteropathogenic e. Coli using a bfpa gene-based electrochemical sensor. Microchim. Acta 2013, 180, 1233-1240. [CrossRef]

12. Tharad, S.; Promdonkoy, B.; Toca-Herrera, J.L. Lipid phase influences the binding of bacillus thuringiensis cyt2aa2 toxin on model lipid membranes. Biochem. Biophys. Res. Commun. 2019, 511, 409-415. [CrossRef] [PubMed]

13. Pettersson, B.; Rippere, K.E.; Yousten, A.A.; Priest, F.G. Transfer of bacillus lentimorbus and bacillus popilliae to the genus paenibacillus with emended descriptions of paenibacillus lentimorbus comb. Nov. And paenibacillus popilliae comb. Nov. Int. J. Syst. Bacteriol. 1999, 49, 531-540. [CrossRef] [PubMed]

14. Wang, D.-B.; Tian, B.; Zhang, Z.-P.; Deng, J.-Y.; Cui, Z.-Q.; Yang, R.-F.; Wang, X.-Y.; Wei, H.-P.; Zhang, X.-E. Rapid detection of bacillus anthracis spores using a super-paramagnetic lateral-flow immunological detectionsystem. Biosens. Bioelectron. 2013, 42, 661-667. [CrossRef] [PubMed]

15. Knurr, J.; Benedek, O.; Heslop, J.; Vinson, R.B.; Boydston, J.A.; McAndrew, J.; Kearney, J.F.; Turnbough, C.L. Peptide ligands that bind selectively to spores of bacillus subtilis and closely related species. Appl. Environ. Microbiol. 2003, 69, 6841-6847. [CrossRef] [PubMed]

16. Nicholson, W.L.; Munakata, N.; Horneck, G.; Melosh, H.J.; Setlow, P. Resistance of bacillus endospores to extreme terrestrial and extraterrestrial environments. Microbiol. Mol. Biol. Rev. 2000, 64, 548-572. [CrossRef]

17. Cheng, H.-W.; Chen, Y.-Y.; Lin, X.-X.; Huan, S.-Y.; Wu, H.-L.; Shen, G.-L.; Yu, R.-Q. Surface-enhanced raman spectroscopic detection of bacillus subtilis spores using gold nanoparticle based substrates. Anal. Chim. Acta 2011, 707, 155-163. [CrossRef]

18. Sengupta, A.; Shende, C.; Farquharson, S.; Inscore, F. Detection of bacillus anthracis spores using peptide functionalized sers-active substrates. Int. J. Spectrosc. 2012, 2012, 6. [CrossRef]

19. Dalton, R. Genetic sleuths rush to identify anthrax strains in mail attacks. Nature 2001, 413, 657-658. [CrossRef]

20. Skottrup, P.D.; Nicolaisen, M.; Justesen, A.F. Towards on-site pathogen detection using antibody-based sensors. Biosens. Bioelectron. 2008, 24, 339-348. [CrossRef]

21. Chenau, J.; Fenaille, F.; Ezan, E.; Morel, N.; Lamourette, P.; Goossens, P.L.; Becher, F. Sensitive detection of bacillus anthracis spores by immunocapture and liquid chromatography-tandem mass spectrometry. Anal. Chem. 2011, 83, 8675-8682. [CrossRef] [PubMed]

22. Li, D.; Rands, A.D.; Losee, S.C.; Holt, B.C.; Williams, J.R.; Lammert, S.A.; Robison, R.A.; Tolley, H.D.; Lee, M.L. Automated thermochemolysis reactor for detection of bacillus anthracis endospores by gas chromatography-mass spectrometry. Anal. Chim. Acta 2013, 775, 67-74. [CrossRef] [PubMed]

23. Weerasekara, M.L.M.A.W.; Ryuda, N.; Miyamoto, H.; Okumura, T.; Ueno, D.; Inoue, K.; Someya, T. Double-color fluorescence in situ hybridization (fish) for the detection of bacillus anthracis spores in environmental samples with a novel permeabilization protocol. J. Microbiol. Methods 2013, 93, 177-184. [CrossRef] [PubMed]

24. Pellegrino, P.M.; Fell, N.F., Jr.; Gillespie, J.B. Enhanced spore detection using dipicolinate extraction techniques. Anal. Chim. Acta 2002, 455, 167-177. [CrossRef]

25. Hathout, Y.; Setlow, B.; Cabrera-Martinez, R.-M.; Fenselau, C.; Setlow, P. Small, acid-soluble proteins as biomarkers in mass spectrometry analysis of bacillus spores. Appl. Environ. Microbiol. 2003, 69, 1100-1107. [CrossRef] [PubMed] 
26. Goodacre, R.; Shann, B.; Gilbert, R.J.; Timmins, É.M.; McGovern, A.C.; Alsberg, B.K.; Kell, D.B.; Logan, N.A. Detection of the dipicolinic acid biomarker in bacillus spores using curie-point pyrolysis mass spectrometry and fourier transform infrared spectroscopy. Anal. Chem. 1999, 72, 119-127. [CrossRef]

27. Farquharson, S.; Grigely, L.; Khitrov, V.; Smith, W.; Sperry, J.F.; Fenerty, G. Detecting bacillus cereus spores on a mail sorting system using raman spectroscopy. J. Raman Spectrosc. 2004, 35, 82-86. [CrossRef]

28. Cowcher, D.P.; Xu, Y.; Goodacre, R. Portable, quantitative detection of bacillus bacterial spores using surface-enhanced raman scattering. Anal. Chem. 2013, 85, 3297-3302. [CrossRef]

29. He, L.; Deen, B.D.; Pagel, A.H.; Diez-Gonzalez, F.; Labuza, T.P. Concentration, detection and discrimination of bacillus anthracis spores in orange juice using aptamer based surface enhanced raman spectroscopy. Analyst 2013, 138, 1657-1659. [CrossRef]

30. Schirhagl, R.; Latif, U.; Podlipna, D.; Blumenstock, H.; Dickert, F.L. Natural and biomimetic materials for the detection of insulin. Anal. Chem. 2012, 84, 3908-3913. [CrossRef]

31. Schirhagl, R.; Lieberzeit, P.A.; Dickert, F.L. Chemosensors for viruses based on artificial immunoglobulin copies. Adv. Mater. 2010, 22, 2078-2081. [CrossRef] [PubMed]

32. Schirhagl, R.; Podlipna, D.; Lieberzeit, P.A.; Dickert, F.L. Comparing biomimetic and biological receptors for insulin sensing. Chem. Commun. 2010, 46, 3128-3130. [CrossRef] [PubMed]

33. Schirhagl, R.; Seifner, A.; Husain, F.; Cichna-Markl, M.; Lieberzeit, P.; Dickert, F. Antibodies and their replicae in microfluidic sensor systems-Labelfree quality assessment in food chemistry and medicine. Sens. Lett. 2010, 8, 399-404. [CrossRef]

34. Yaqub, S.; Latif, U.; Dickert, F.L. Plastic antibodies as chemical sensor material for atrazine detection. Sens. Actuators B Chem. 2011, 160, 227-233. [CrossRef]

35. Jia, M.; Zhang, Z.; Li, J.; Ma, X.; Chen, L.; Yang, X. Molecular imprinting technology for microorganism analysis. TrAC Trends Anal. Chem. 2018, 106, 190-201. [CrossRef]

36. Mujahid, A.; Mustafa, G.; Dickert, F.L. Label-free bioanalyte detection from nanometer to micrometer dimensions-Molecular imprinting and qcms †. Biosensors 2018, 8, 52. [CrossRef]

37. Alexander, C.; Vulfson, E.N. Spatially functionalized polymer surfaces produced via cell-mediated lithography. Adv. Mater. 1997, 9, 751-755. [CrossRef]

38. Findeisen, A.; Wackerlig, J.; Samardzic, R.; Pitkänen, J.; Anttalainen, O.; Dickert, F.L.; Lieberzeit, P.A. Artificial receptor layers for detecting chemical and biological agent mimics. Sens. Actuators B Chem. 2012, 170, 196-200. [CrossRef]

39. Latif, U.; Can, S.; Hayden, O.; Grillberger, P.; Dickert, F.L. Sauerbrey and anti-sauerbrey behavioral studies in qcm sensors-Detection of bioanalytes. Sens. Actuators B Chem. 2013, 176, 825-830. [CrossRef]

40. Martínez-Salas, E.; Martín, J.A.; Vicente, M. Relationship of escherichia coli density to growth rate and cell age. J. Bacteriol. 1981, 147, 97-100. [CrossRef]

41. Howard, G.T. Microbial biodegradation of polyurethane. Recent Dev. Polym. Recycl. 2011, $215,238$.

42. Xu, Z.; Yuan, Y.J. Quantification of staphylococcus aureus using surface acoustic wave sensors. RSC Adv. 2019, 9, 8411-8414. [CrossRef]

(C) 2020 by the authors. Licensee MDPI, Basel, Switzerland. This article is an open access article distributed under the terms and conditions of the Creative Commons Attribution (CC BY) license (http://creativecommons.org/licenses/by/4.0/). 